\title{
The ambient intelligence for the sake of accessibility in residential projects: a proper study to the Brazilian scene
}

\author{
Castañon J.A.B., Maia, M.P.F.' Silva, M.C.C. \\ Pós Graduação em Ambiente Construído (PROAC), Faculdade de Engenharia, UFJF, Juiz de Fora, Brazil
}

\begin{abstract}
The concept of Ambient Intelligence consists of intuitive interfaces embedded in everyday objects that interact with the user and function in an integrated and discrete generating and transmitting information. This article has as objective to present applications that when focused on accessibility criteria, can contribute to the work of architects during the design of residential projects. In Brazil, pioneering projects are already being developed and the use of Ambient Intelligence systems are already widespread, both by private and public, however much care technologies developed in other countries.
\end{abstract}

Keywords: Ambient Intelligence, Home Automation, Accessibility

\section{Introduction}

Life expectancy in the world for both sexes is 66.57 years according to the CIA World Factbook (2009) and 67,2 years according to World Population Prospects of the United Nations Report (2005-2010). In Brazil, this number is 73 years and in case of women reaches 77 years, according to Brazilian Geography and Statistics Institute (2010). Also according to the UN, approximately $15 \%$ of the population has some type of disability, the same proportion is found among the Brazilian population.

The concept of Ambient Intelligence consists of intuitive interfaces embedded in everyday objects that interact with the user and work seamlessly and discreetly, generating and transmitting information. Such systems, used in environments inhabited by elderly or cognitive and sensory disabled, allow that changes in the resident's behavior like health, diet and tasks performed are accompanied by family members and doctors at a distance, allowing more independence, comfort and safety.

\section{AmI and the accessibility}

For Ambient Intelligence Systems work effectively in helping people with special needs, they must meet the requirements of discretion (should work in an "invisible" mode in order to free its users from the need to make decisions), adaptation (must provide a wide range of configuration options that are combined to suit individual needs) and anticipation (must anticipate the desires of users without the need for direct interactions).

These applications when focused on accessibility criteria, can contribute to the work of architects during the design of residential projects. The adequacy of needs of these user profiles should be considered at an early stage of development of any automated system and not simply adapted to generic designs.

Home automation projects aimed at improving the quality of life of people dependent have been developed worldwide. As an example we can cite the system developed by the Center for Research in Micro / Nano Technologies, which consists of a device capable of diagnosing various cancers and other diseases without the need for visits to laboratories and invasive procedures. Another important project is conducted by the Polytechnic University of Valencia, called "AmIVital" developed through the use of smart devices intended exclusively for people with special needs in order to promote services and supports custom in favor of a more independent home life. Also we can mention the project "Persona," 
which aims to identify emergency situations and communicate them to health services and turn off electronics automatically. In general, these projects meet the following types of needs: monitoring, location, guidance and support the users. In Brazil, pioneering projects are being developed by the Intelligent Robotics Laboratory at the Federal University of Rio Grande do Sul, especially the creation of a software that allows interaction between quadriplegics and computerized systems that, among other duties, help in household chores. The use of Ambient Intelligence Systems is already widespread nationally, both by private and public iniciatives, but largely import technologies developed in other countries.

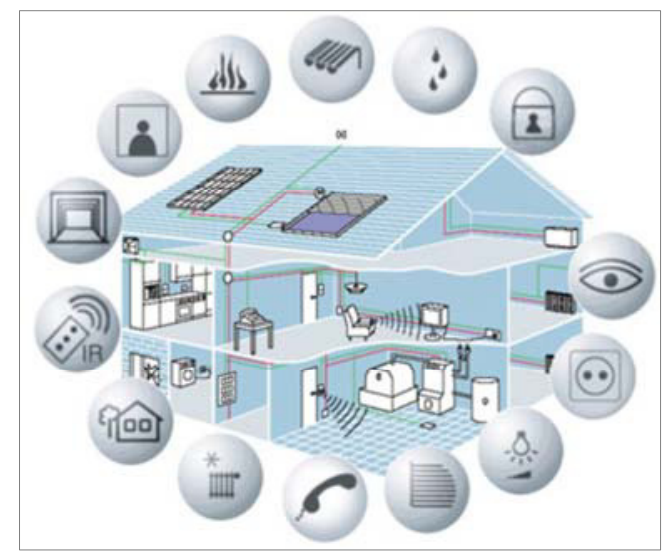

Fig.1. Domotic

Source: http://www.webmarketing.al/domotizim-ambientesh

\section{Application in the world and Brazil}

In 2003, the concept of Smart Home was already being released in Brazil through the II Innovation Salon in São Paulo. This event was a house of $600 \mathrm{~m} 2$ built completely, in $200 \mathrm{~h}$, supported by four workstations with software and hardware specific. Were presented modern totally integrated automation solutions, including: Central Electric Automation, Connectivity Center, Central Personnel Monitoring, Central Monitoring Image Distance, Voice Command, Control, Lighting, sound and visual flags, Cleansers, phones for the Deaf, among others. Technologies already much widespread such as videoconferencing, have also been associated with previously cited, allowing meetings at home, for example, which would facilitate access for the disabled to the labor market. Importantly highlight that the target audience of this exhibition was not only composed of people with special needs, since the high level of comfort pro- vided by this set of technologies was also appealing to other audiences, especially to young people.

Studies in search of new technologies are being developed, among many projects we can mention wearable computers, appointed by Viseu (2003) apud DONATI (2004) as bodynets, by emphasizing the interaction between body, technology and environment. According DONATI (2004), these products can be considered active agents, by synthesizing contemporary trends such as mobility, continuous information access, personalization, control and networking. In addition to bringing facilities, these devices transform and shape some physical activity and cognitive functions, because it is designed in an integrated manner with the user's movement, inserting themselves in their daily activities. An application of wearable computing that is important for society, it is in the disabled people that will be in possession of cameras, microphones and other sensors to enjoy a relatively normal life like most people. The wardrobe helps especially for home-care services, it relies on studies and research of health related products, such as the development of clothes that monitor blood pressure, heart rate and body temperature, and diagnose users without requiring complex system of wires and electrodes. This monitoring work, mostly via bluetooth, works informing emergency centers through SMS, e-mail or phone, in addition to forming a database of patient history.

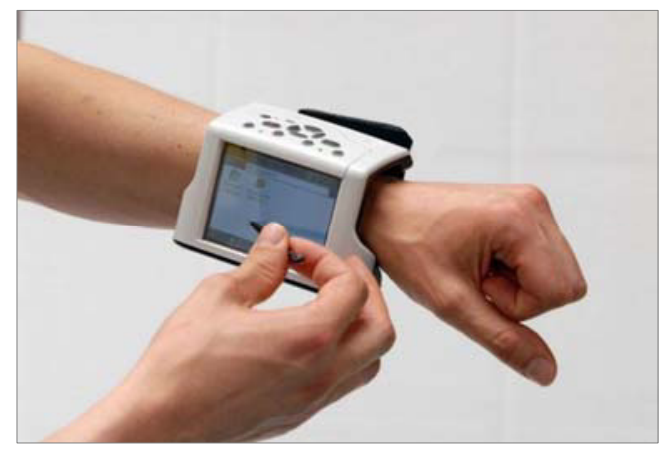

Fig.2. Wearable Computer Integrating Bluetooth, Wi-Fi, GPS Source: mobilitysite.com

The main obstacles that can be identified in the adoption of this technology in Brazil converge on four main issues: privacy, infrastructure, interfaces and social aspects. Personal information may be accessed and filed by anyone without the perception and the users consent. Because of this, they should have the right to decide what information they want 
becomes available. As for infrastructure, is still needed a breakthrough especially in regard to wireless networks and software engineering. Because of the possibility of failure, it is important to have the option to operate "outside the system" when necessary. It is also important to ensure that people of different levels of education are able to interact with applications without the risk of confusion, stress or frustration. Finally, special care must be taken with the social implications that adoption of this system can cause. In Latin American countries in general, the need for social interaction tends to be higher than in other countries, much due the cultural reasons. The independence provided by this technology may result in the isolation of these individuals, when it is increasingly necessary to include them in activities common to the society in which they live.

\section{References}

[1] Abascal, J.; et al. Managing Intelligent Services for People with Disabilities and Elderly People. Computer Science, v, 5615, 2009. 623-30. Available in:http://www.springerlink.comcontent/078n257806u70203/. Accessed: jun. 2011.

[2] Casas, R; et al. User Modelling in Ambient Intelligence for Elderly and Disabled People. Computer Science, v.5105, 2008. P. 114-122. Available in: < http://www.springerlink.com/content/5085668312150127/ >. Accessed: jun. 2011.
[3] Delgado, A.R.; et al. Assistive Human-Machine Interfaces for Smart Homes. Glyndŵr University Research Online, jan. 2007. 13p. Available in: < http://epubs.glyndwr.ac.uk >. Accessed: jun. 2011.

[4] Dias, C.L.A.; Pizzolato, N.D. Domótica: Aplicabilidade e Sistemas de Automação Residencial. Vértices, dez. 2004. 32p. Available in: http://essentiaeditora.iff.edu.br/index.php/vertices/article/view File/98/86 >. Accessed: jun. 2011.

[5] Donati, L.P. Computadores vestíveis: convivência de diferentes espacialidades. Conexão - Computação e Cultura, UCS, Caxias do Sul, v.3, n. 6, p. 93 -102, 2004.

[6] Howard, S; Kjeldskov, J; Kkov, M.V. Pervasive computing in the domestic space. Pers Ubiquit Comput, v. 11, 2007. 329. 333. Available in:

http://unimelb.academia.eduSteveHoward/Papers/332341/Perv asive_Computing_In_the_Domestic_Space.>. Accessed: jun. 2011.

[7] Messis, A.F. Edifícios "Inteligentes": a domótica aplicada à realidade brasileira. 2007. 57 p. Monograph (Control and Automation Engineering) - UFOP, Ouro Preto.

[8] Norman, D.A. Ambient Intelligence: A New Multidisciplinary Paradigm. IEEE transactions on systems, man, and cybernetics, v.35, n.1, jan. 2005. 6p. Available in: $<$ http://ieeexplore.iee.org/Xplore/ login.jsp?url= http $\% 3 \mathrm{~A} \% 2 \mathrm{~F} \% 2$ Fieeexplore $\quad$.ieee.org $\%$ 2Fiel 5 $\% 2 \mathrm{~F} 3468 \% 2 \mathrm{~F} 29969 \% 2 \mathrm{~F} 01369340$.

pdf\%3Farnumber\%3D1369340\&authDecision $=-203>$. Accessed: jun. 2011.

[9] Panisson, L.S. Dos computadores vestíveis às roupas pensantes: os avanços tecnológicos a serviço da moda e da comunicação. In: Simósio Nacional ABCIBER, 3, 2009, São Paulo. Anais... São Paulo: ESPM/SP, nov. 2009. 11 p. 